\title{
Study of Management of Scalp Defect- Our Experience in a Tertiary Care Center of Vindhya Region, a Remote Area of MP
}

\author{
Saurabh Saxena ${ }^{1}$, Darshan B. Y. ${ }^{2}$ \\ ${ }^{1}$ Department of Surgery, Shyam Shah Medical College, Rewa, Madhya Pradesh, India. \\ ${ }^{2}$ Department of Surgery, Shyam Shah Medical College, Rewa, Madhya Pradesh, India.
}

\section{ABSTRACT}

\section{BACKGROUND}

Aetiology of the scalp defects may be burns, trauma, avulsion, infection, resection for neoplasm or congenital defects, the goals \& principles are similar, and their repair is dependent upon their location, size and depth. In the case of the scalp, the repair of even small defects is complicated. We wanted to assess the epidemiology, etiological factors, type and site of distribution, various modalities, overall cosmetic effect and function of both donor as well as recipient sites of scalp defects. We also wanted to evaluate the epidemiological and aetiological factors influencing the various modalities of scalp defect management and the overall cosmetic effect on both donor as well as recipient site.

\section{METHODS}

A descriptive study was conducted at Sham Shah Medical College and associated SGM Hospital, Rewa, which is also known as Vindhya region of Madhya Pradesh. A total of 44 cases of scalp defects, that were treated in the department of surgery over a period of 18 months from May 2018 to November 2019 constitute the material of this study. Patients were included in the study after obtaining an informed consent. One-year follow-up of the patients was done,

\section{RESULTS}

26 cases [59.01\%] of scalp defect were repaired with transposition flap; rotation flap was done in 2 cases [4.45\%], bipedicled flap was done in 2 cases [4.45\%], double opposing rotational flap was done in 01 case [2.27], S.T.G. was done in 7 cases [15.9\%], and primary closure was done in 6 cases [13.63\%]. In our study $59.09 \%$ cases are due to trauma and occur in second to fourth decade out of which 26 patients have exposed bone, and out of 26 patients, 09 patients have fracture of bone.

\section{CONCLUSIONS}

Scalp reconstruction depends on the nature and the region of the defect. A range of reconstruction techniques have been described. The quality of the residual scalp is critical for performing a local flap. Local flaps are the reference for the reconstruction of such defects. Knowledge of scalp anatomy is essential for preparing these flaps. The parietal zone is the location offering the greatest flap mobilization possibilities. A review is provided of the different techniques for the reconstruction of large scalp defects.

\section{KEY WORDS}

Scalp Reconstruction, Scalp Defects, Rotation \& Transposition Flaps
Corresponding Author:

Saurabh Saxena,

Block 1, Flat No. 3,

New Doctors Colony,

Arjun Nagar, Rewa-486001,

Madhya Pradesh, India.

E-mail: saurabh197832@yahoo.in

DOI: $10.14260 /$ jemds $/ 2020 / 458$

How to Cite This Article:

Saxena S, Darshan BY. Study of management of scalp defect- our experience in tertiary care center of Vindhya region, a remote area of MP. J. Evolution Med. Dent. Sci. 2020;9(30):20972102, DOI: 10.14260/jemds/2020/458

Submission 28-01-2020,

Peer Review 15-06-2020

Acceptance 22-06-2020,

Published 27-07-2020.

Copyright (C) 2020 JEMDS. This is an open access article distributed under Creative Commons Attribution License [Attribution 4.0 International (CC BY 4.0)] 


\section{BACKGROUND}

The scalp is unique and is highest point of the body, most exposed and usually not covered by clothing. These factors make it vulnerable to various injuries. Aetiology of scalp defects may be trauma, burns, avulsion, infection, resection for neoplasm, or congenital defects, the goals \& principles are similar. $(1,2,3)$ Therefore the decision-making process behind a successful outcome requires a solid knowledge of anatomy, a clear evaluation of the defect, the recognition of relevant patient attributes, and the knowledge of a variety of reconstruction options available. Knowledge of scalp anatomy is essential for preparing these flaps.(4) The skin layers of the scalp are easy to remember: SCALP (S: skin; C: subcutaneous tissue; A: aponeurotic layer; L: loose areolar tissue; P: pericranium).(5) The skin in this region is the thickest in the body. It is resistant, very scantly elastic, and is covered with hair. $(3,5,6)$ The subcutaneous tissue in turn contains the blood vessels, nerves and hair follicles. ${ }^{(5,7)}$ The main arteries irrigating the scalp are the superficial temporal artery, with its frontal and parietal branches, the posterior auricular artery and the occipital artery - all of which are branches of the external carotid artery - and the supraorbital and trochlear arteries (branches of the internal carotid artery).(5,6) Local flaps must be based on one or two vascular pedicles of the scalp to afford a large rotation angle - thereby facilitating closure of the defect. $(1,5,8)$ The repair of such defects is dependent upon their location, size and depth.(2) Unlike in other head and neck areas where local flaps are used to repair large defects, in the region of the scalp the repair of even small defects is complicated.(1,3,4,9) Rotation, advancement and trans positioning scalp flaps are the reference for reconstructing these defects(11). On the other hand the skin of the scalp lacks laxity and primary closure of wounds greater than $2 \mathrm{~cm}$ is often not possible.

Multiple reconstructive options exist that includes, primary wound repair, healing by secondary intention, and the use of skin grafts, local tissue flaps, regional myocutaneous flaps, and micro vascular free flaps.

Although primary closure is feasible in some case, the mainstay of treatment involves local tissue rearrangement with or without split skin grafting. In addition, free tissue transfer is an important adjunct to therapy in patients with poor local tissues. There are a number of local flap techniques: single or multiple, and with or without skin grafting to close the donor defects. Single flaps in turn comprise rotation, advancement, Trans positioning, bipedicle trans positioning, VY advancement and rhomboidal flaps, etc. $(1,9,6,10)$ Multiple flaps in turn include the triple-flap technique described by Orticochea, the triple rotation (pinwheel) flap, double rotation flap, triple rhomboid flap, and V-Y-S scalp plasty technique, etc. $(1,2,9,11,12)$ Tissue expansion is also one of the most important armamentaria for aesthetic scalp reconstruction after burn(11,12). Each reconstructive plan must be carefully tailored to meet the unique requirements of the patient and associated wound characteristics

\section{Objectives}

To study the epidemiological, etiological factors influencing the various modalities of scalp defect management and to study the overall cosmetic effect on both donor as well as recipient site.

\section{METHODS}

This descriptive Study was conducted at Sham shah medical college and associated SGM Hospital REWA which is also known as Vindhya region of Madhya Pradesh. Patients who attended the hospital facilities, either the outpatient department or Indore patients were descriptively included in the study. A total of 44 cases of scalp defects, that were treated in the department of surgery over a period of 18 months from May 2018 to November 2019 constitute the material of this study. Patients were included in the study after obtaining informed consent.

Patients either came directly to hospital or were referred from outside. Once the patient was seemed hemodynamically stable with no life-threatening issues pending, a thorough inquiry was made into the mode of injury, the mechanism of injury, primary care taken, delay before presentation and associated medical conditions. Patients presenting in outdoor department were also fully investigated in the form of blood investigations, $x$ rays of, high definition CT scan with 3D reconstruction wherever indicated.

After fully investigating the patient, treatment plan is made, and reconstruction done according to the plan. Sometimes, multistage surgeries were required. Patients were followed up regularly after discharge to monitor the outcome of treatment modality, to assess complications emanating in the process of care and to revise certain steps, if necessary. Regional skin, fascial, or muscle flaps are protected from direct pressure for 7-10 days following the procedure. Written and photographic records were maintained for the purpose of analysis. Most of the patients were discharged only after complete healing or significant healing had occurred.

\section{RESULTS}

Trauma was the most common etiological agent in our study and account $59.09 \%$ of total cases. Electrical injuries were the second most common etiological factor for scalp defect. Other etiological factors are like, avulsion injuries, benign lesion, haemangioma and infected implant. [table 1]

\begin{tabular}{|cccccc|}
\hline Age Group & Trauma & Assault & Fall & Electrical Burn & Others \\
$0-10$ & 5 & 0 & 0 & 1 & 1 \\
$11--20$ & 6 & 0 & 0 & 4 & 4 \\
$21-30$ & 6 & 1 & 0 & 1 & 2 \\
$31-40$ & 6 & 0 & 0 & 0 & 0 \\
$41-50$ & 1 & 0 & 0 & 1 & 3 \\
$51-60$ & 2 & 0 & 0 & 0 & 0 \\
\multicolumn{7}{c}{ Table 1. Age Group Affected vs. Aetiology } \\
\hline
\end{tabular}

The scalp defects are commonest among the young adults in second and third decade that is $50 \%$ of total cases and the mean age of our study group for which reconstructive procedure was done is 24.79 years. s. Below ten years of age group patients, five cases were seen which usually occur during playing on the roadside. Above fifty years of age group only 02 cases were present which have road traffic accident on 
highway. [table 1], we had 44 cases of scalp reconstruction, with a case of 4 years of old baby to 57 years old man. In this study of 44 cases of scalp defects, $34.09 \%$ of the subjects belonged to age group of $11-20$ years which was the largest group. Second largest group belongs to age group $31-40$ years which includes $18.18 \%$ cases of total 44 cases. No patients were more than 60 years of age. In present study only $15.9 \%$ patients were under 10 years of age.

In our study 7 cases of electrocution included in which 4 cases $(57.14 \%)$ belongs to second decade age group. Out of seven cases six cases are male and one was female. Two cases of avulsion of scalp included, both are female and having injury while working on moving machinery were there long hair entangle on machine belt.

Two cases of implant exposed at the occipital region were included which was operated for neurological problem. The mean size of the defects in its longest dimensions was $4.5 \mathrm{~cm}$ while bone was exposed in 26 cases. There is male preponderance as they are more engaged in outdoor activities. Male to Female ratio is 3.88 [.Table 2]

\begin{tabular}{|ccccc|}
\hline Study & Total Cases & Male & Female & Ratio \\
Musa Mateev et. Al ${ }^{13}$ & 17 & 14 & 3 & 4.66 \\
${\text { Mario Iger et. } \mathbf{A l}^{14}}$ & 78 & 58 & 20 & 2.9 \\
${\text { Camelial Tamus et. } \mathrm{Al}^{15}}$ & 13 & 11 & 2 & 3.6 \\
Abdul Memon et. Al & 38 & 28 & 10 & 2.8 \\
Present Study & 44 & 35 & 9 & 3.88 \\
Table 2. Comparative Incidence of Sex Distribution in Different Series \\
\hline
\end{tabular}

Left Temporoparietal region was most common site of scalp defect (31.8\%).72.72\% of the patients had associated injuries apart from scalp defect. [Table 3]

\begin{tabular}{|cc|}
\hline Site of Defect & No. Patients \\
Right Parietal & 1 \\
Right Temporal & 1 \\
Left Parietal & 4 \\
Frontal & 3 \\
Left Parieto-temporal & 8 \\
Right Fronto-parietal & 6 \\
Left Fronto-parietal & 1 \\
Left Fronto-temporal & 3 \\
Left Fronto-parieto-temporal & 5 \\
Occipital & 10 \\
Whole Skull & 2 \\
Table 3. Site of Defect & \\
\hline
\end{tabular}

In our study, head injuries were seen in $56.81 \%$ cases, limb injuries in $4.5 \%$ cases. In our study out of 44 cases 26 cases have exposed bone and out of 26 cases 9 cases have fracture of the bone. In our study transposition flap along with split thickness grafting was most commonly used.16

In only 07 cases the primary closure found feasible, while all remaining cases required some reconstructive procedure. Transposition flap was the most common procedure (59.09\%) while skin graft alone or in combination with other techniques was the second most common procedure performed in our study. [Table 4].

We used the transposition flap in 26 cases, it is useful flap that allow to closure mild to moderately large defect, unlike the rotation flap which obliges to construction a big scar in one direction. In 2 cases we did the rotation flap to cover the exposed implant at occipital region with primary closure of the secondary defect. In 2 cases we did bipedicled flap to cover the scalp defect. We did 7 cases of split skin grafting in our study for scalp defect reconstruction.[Table 5]

\begin{tabular}{|c|c|c|c|c|c|c|}
\hline : & 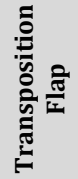 & 营 & 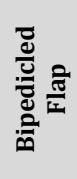 & 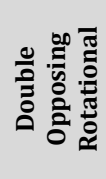 & نَ & 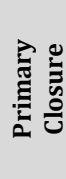 \\
\hline RTA & 20 & 0 & 1 & 0 & 5 & 0 \\
\hline Avulsion Injuries & 0 & 0 & 0 & 0 & 2 & 0 \\
\hline Infected Implant & 0 & 2 & 0 & 0 & 0 & 0 \\
\hline Benign Lesions & 0 & 0 & 0 & 0 & 0 & 5 \\
\hline Electrical Burns & 6 & 0 & 1 & 0 & 0 & 0 \\
\hline Hemangioma & 0 & 0 & 0 & 1 & 0 & 0 \\
\hline Assault & 0 & 0 & 0 & 0 & 0 & 1 \\
\hline
\end{tabular}

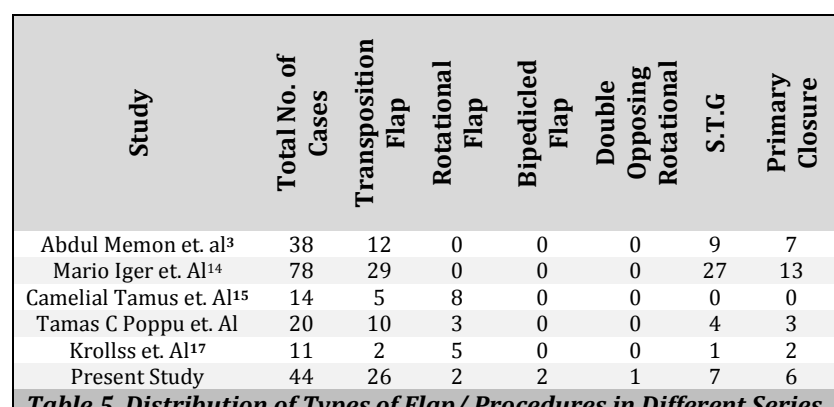

In two cases out of seven skin grafting cases, whole scalp skin grafting was done, which was occur due to avulsion injury by machine. There was no obvious loss of function of donor site in the long run.

\section{DISCUSSION}

Forty-four patients were treated during a period from May 2018 to November 2019. Twenty-nine patients were admitted directly through plastic surgery outpatient department while the rest of the patient were referred from Orthopaedic/ Neurosurgery department. All the patients were operated as elective except two cases of scalp replantation which were operated on emergency basis. The management of scalp defects remains a continuous challenge to the reconstructive surgeon worldwide. There are many options for repairing scalp defects. $(1,10,18)$ Healing by secondary intention is a possibility for repairing scalp defects, though this option is not applicable in the presence of large defects with a lack of pericranium. $(1,19,20)$ The use of skin grafts for reconstruction requires an intact pericranium to supply vascularization to the repaired zone. In the absence of a pericranium, and if grafting is the only repair option, perforations in the external cortical layer of the skull allow the formation of granulation tissue that would improve the prognosis of the second-step skin graft. $(1,4,14)$

Locale flap are mobilized to cover scalp defects.(3) Peri cranial and fascial flaps have also been described in which the pericranium, the frontal aponeurosis or temporoparietal fascia are mobilized below the donor zone and are rotated. The advantage of these micro vascularized flaps is that they allow the repair of large defects with highly vascularized tissue, in a single surgical step. ${ }^{(1,19)}$ A basic principle in surgery is to first 
use the simplest technique available. $(2,12,21,22)$ This study was done to access outcome of management of scalp injury in our unit. In our study, the mean age was 24.79 yrs. Abdul Memon et al, ${ }^{3}$ Mateev ma et al. ${ }^{13}$

While in study by Mario, Igor Luigi et. $\mathrm{Al}^{14}$ the age of the patients ranged from 1 day old to 84 years, with a mean age of 68 years. In another study by Antostane, Yolanda Hristo et. $\mathrm{Al}^{23}$ the age of the patients ranging from 11 to 86 years, the mean age was 61.7 years. Study by Cameliatamas et al. ${ }^{15}$ shows range of patients age 37 and 85 years, with mean age of 59 years. Most of the patients in our study were males and they had scalp defect mostly due to direct trauma and electric burns, this reflects the fact that male while performing most of outdoor activities are more prone to trauma, and females of our society remain at home for domestic affairs are largely protected

Among 44 patients; 35 were male and 9 were female. Ratio of male to female is 3.88 as shown in table 4 . While in study by Mario cherubino, Dominic Taibi et al ${ }^{14}$ ratio of male to female was 2.9. [Table 1]. In study by Cameliatamas Lucian, Dana et al ${ }^{15}$ ratio of male to female was 3.66. Trauma was the most common etiological agent in our study and account $59.09 \%$ of total cases. In our study out of 26 cases of trauma 18 cases belongs to second and fourth decade of age group indicating outdoor activity and careless driving. Below ten years of age group patients, five cases were seen which usually occur during playing on the roadside. Above fifty years of age group only 02 cases were present which have road traffic accident on highway Abdulmemon et al. ${ }^{3}$ Van Driel et al. ${ }^{24}$ The particular age distribution in posttraumatic scalp defect due to certain reasons these are, the prevalent age group is more exposed to risk which include driving, outdoor working, violence, sports etc. Second largest group of aetiology was electrical burn in our study. The injuries commonly occur due to contact with either high tension wire or domestic electrical supply accidently during work. Most of the victim of electrical burn belongs to second decade (11-20) suggesting that electrocution can occur while careless working and illegal handling of the lines leads to chances of accidental contact with high tension cables. Calvaria electrical burns pose a difficult challenge for both plastic surgeon and neurosurgeon. Compared to conventional burns, these injuries are characterized by an increased morbidity and mortality. Deep burns of the scalp and skull can be caused by high-voltage electrical injuries, 25,26,27

In our study 7 cases of electrocution included in which 4 cases $(57.14 \%)$ belongs to second decade age group. Out of seven cases six cases are male and one was female. While in study by Mohamed Makboul et al during 2.5 yrs. duration for reconstruction of paediatric scalp defects after electrical burns, involved 10 patients who suffered from electrical burn injury of the scalp and managed in burns unit. Out of 10 patients 9 were male and 1 female. Out of 10 patients 7 were belongs to age group ranging $11-20(70 \%)$. This is in accordance with our study in which second decade have majority of the cases benign lesions were third major group of aetiology which includes case of Nevus sebaceous of Jadassohn, dermoid and infected sebaceous cyst. In our study two cases of avulsion of scalp included, both are female and having injury while working on moving machinery were there long hair entangle on machine belt. In our study two cases of implant exposed at the occipital region were included which was operated for neurological problem. In this study, scalp defects were due to posttraumatic, electric injury post infectious causes, avulsion injuries, and benign lesion. The mean size of the defects in its longest dimensions was $4.5 \mathrm{~cm}$ while bone was exposed in 26 cases. Left Temporoparietal region most common site was scalp defect present (31.8\%). Whole skull involve in case of avulsion injury were entanglement of long hair in moving machinery leads to avulsion of scalp present in 02 cases. In the present study, $72.72 \%$ of the patients had associated injuries apart from scalp defect. In our study, head injuries were seen in $56.81 \%$ cases, limb injuries in $4.5 \%$ cases.

Steidler N E et al ${ }^{16}$ noted head (51\%), injury concomitant with scalp injuries. In our study out of 44 cases 26 cases have exposed bone and Out of 26 cases 9 cases have fracture of the bone. In our study transposition flap along with split thickness grafting was most commonly used. $(7,19,20)$ In only 07 cases the primary closure found feasible, while all remaining cases required some reconstructive procedure. Transposition flap was the most common procedure (59.09\%) while skin graft alone or in combination with other techniques was the second most common procedure performed in our study. Local flaps are one of the mainstays of scalp reconstruction in this study. These flaps can provide healthy, durable, and hair- bearing skin and may aid in healing of patients with compromised wounds. Obviously, the residual scar is always well covered with hair. No residual pain or hypertrophic scar has been observed. They may be performed in small and moderate defects, where good quality of local tissue is present. When applying this surgical approach, special attention should be paid to the area of the hairline and sideburns, which have to be preserved as much as possible. The donor site should be selected in the least aesthetically sensitive area depending on the defect. Flaps with primary closure may be applied in patients with elastic scalp tissue, a moderately sized defect, and a location in the central or parietal area of the scalp. When the wound is peripheral or more than one zone is involved, the flaps must be both transposition flaps and larger in size, large transposition flaps with skin grafting for the donor area were used. Apart from the size and position of the defect, another important factor to be considered is wound depth. Compared to regional and free flaps, treatment with local flaps is a safe, relatively short, and simple procedure unlikely to cause any major complications or demanding special postoperative care. We used the transposition flap in 26 cases, it is useful flap that allow to closure mild to moderately large defect, unlike the rotation flap which obliges to construction a big scar in one direction. [Table 5]

In 2 cases we did the rotation flap to cover the exposed implant at occipital region with primary closure of the secondary defect. In 2 cases we did bipedicled flap to cover the scalp defect, Abdul Memon et al,3 Mateev Ma etal.13 While in study by Mario Iger et al ${ }^{14}$ Transposition flap done in 29 cases out of 78 cases. Skin grafting is an excellent option if the defect does not involve the pericranium plane. We did 7 cases of split skin grafting in our study for scalp defect reconstruction. In study by Abdul Memon et al ${ }^{3}$ cases covered by SSG. In other study by Tamas C Poppu et al 4 case having SSG. In two cases out of seven skin grafting cases, whole scalp skin grafting was done, which was occur due to avulsion injury by machine. In 
our study one case of haemangioma of scalp at occipital region was included. Primary closure with adjacent tissues may seem like an appropriate first choice for closure of small scalp defects. However, because of the limited elasticity of scalp tissues, usually defects less than $2.5 \mathrm{~cm}^{2}$ are amenable to direct closure. Primary closure was done in six cases which were present either over the occipital region or the parietal region. The laxity of tissue of the occipital and parietal region leads to closure of the defect. In our study, the tissue expansion has not been used. The free flap procedure is a good option in large area defects. We performed a reconstruction of scalp defect by anastomosis of the avulsed scalp tissue by microsurgical procedure $(28,14)$. We used the superficial temporal artery for anastomosis and two venous repairs attempted to prevent flap congestion and subsequent venous insufficiency. Later the flap develop necrosis may be because of delay. After necrosis of replanted scalp flap debridement was done and after granulation split skin grafting was done. Putting together the finding of this study showed that transposition flap and grafting were the main stay of the treatment in majority of patients according to the tissue defect. The postoperative complications seen in this study include wounds infection and partial split skin graft loss, necrosis of flap, seroma and donor site infection. These cases respond well to the conservative management that includes antiseptic dressing and use of antimicrobial agents. In the early and late postoperative period, the qualities of coverage and recipient and donor morbidities were followed up. In all cases, complete tissue coverage has been achieved.

\section{CONCLUSIONS}

We evaluated various procedures for repairing various sizes of scalp defects located on different sites of scalp by means of local flaps and partial-thickness skin graft. Scalp reconstruction depends on the nature and the region of the defect. A range of reconstruction techniques have been described. The quality of the residual scalp is critical for performing a local flap. Local flaps are the reference for the reconstruction of such defects. Knowledge of scalp anatomy is essential for preparing these flaps. Parietal zone is the location offering the greatest flap mobilization possibility. Shortening of surgical time compared with other techniques, simplicity of the surgical procedure, minimum morbidity of skin graft donor area and satisfactory aesthetic outcome make the above mentioned method an adequate option for repairing defects of this kind.

Financial or Other Competing Interests: None.

\section{REFERENCES}

[1] Alpert BS, Buneke HJ, Mathes SJ. Surgical treatment of the totally avulsed scalp. Clin Plast Surg 1982;9 (2):145-59.

[2] Arnold PG, lrons GB. The greater omentum: extensions in transplantation and free transfer. Plast Reconstr Surg 1981;67 (2):169-76.
[3] Memon AR, Kumar M, Shaikh BF, et al. Surgical reconstruction of scalp. Medical Channel 2010;16 (4):578-81.

[4] Arneja JS, Gosain AK. Giant congenital melanocytic nevi. Plast Reconstr Surg 2007;120:26e-40e.

[5] Cupp CL, Larrabee Jr WF. Reconstruction of the forehead and scalp. Operative Techniques in Otolaryngology Head \& Neck Surgery 1993:4 (1):11-7.

[6] Demir Z, Velidedeošlu H, Celebiošlu S. V-Y-S plasty for scalp defects. Plast Reconstr Surg 2003;112 (4):1054-8.

[7] Chavoin JP, Gigaud M, Clouet M, et al. The reconstruction of cranial defects involving scalp, bone and Dura following electrical injury: report of two cases treated by homograft of free groin flap and cranioplasty. Br J Plast Surg 1980;33 (3):311-7.

[8] Del Campo JA, De Marcos JA, Del Castillo JL, et al. Local flap reconstruction of large scalp defects. Med Oral Patol Oral Cir Bucal 2008;13 (10):e666-e70.

[9] Angelos PC, Downs BW, Baker SR. Editorial comments. In: Baker SR, Swanson NA, eds. Local flaps in facial reconstruction. Mosby 1995: p. 439-41.

[10] Guerrissi J0. Reconstruction of large defects in the scalp with fasciocutaneous flaps. Scand J Plast Reconstr Surg Hand Surg 1999;33 (2):217-24.

[11] Onishi K, Maruyama Y, Hayashi A, et al. Repair of scalp defect using a superficial temporal fascia pedicle VY advancement scalp flap. Br J Plast Surg 2005;58 (5):67680.

[12] Sharma RK, Tuli P. Occipital artery Island V-Y advancement flap for reconstruction of posterior scalp defects. J Plast Reconstr Aesthet Surg 2010;63 (3):410-5.

[13] Mateev MA, Beermanov KA, Subanova LK, et al. Shapemodified method using the radial forearm perforator flap for reconstruction of soft-tissue defects of the scalp. J Reconstr Microsurg 2005;21 (1):21-4.

[14] Cherubino M, Taibi D, Scamoni S, et al. A new algorithm for the surgical management of defects of the scalp. 2013;2013:916071.

[15] Tamas C, Popa L, Turliuc D, et al. Surgical reconstruction in scalp defect. Clinics of Plastic and Reconstructive Surgery 2005;1 (2):83-6.

[16] Steidler NE, Cook RM, Reade PC. Incidence and management of major middle third facial fracture at the Royal Melbourne Hospital. A retrospective study. Int J Oral Surg 1980;9 (2):92-8.

[17] Kroll SS, Margolis R. Scalp flap reconstruction with primary donor site closure. Annals Plast Surg 1993;30 (5):452-5.

[18] Hussain W, Mortimer NJ, Salmon PJM, et al. Galeal/ periosteal flaps for the reconstruction of large scalp defects with exposed outer table. Br J Dermatol 2010;162 (3):684-6.

[19] McWilliams CA. Principles of the four types of skin grafting. With an improved method of treating total avulsion of the scalp. JAMA 1924;83 (3):183-9.

[20] Molnar JA, DeFranzo AJ, Marks MW. Single-stage approach to skin grafting the exposed skull. Plast Reconstr Surg 2000;105 (1):174-7.

[21] Vicharova-Romanska PT, Zaiakova I, Iankov D, et al. Reconstruction of the large defects of the scalp with local fasciocutan flaps. Khirurgiia (Sofiia) 2004;60:16-9. 
[22] Zhang GL, Zhang M, Jing H, et al. Repair of scalp defect using V-Y-S rotation flap. Zhongguo Gu Shang 2008;21 (5):375-6.

[23] Zayakova Y, Stanev A, Mihailov H, et al. Application of local axial flaps to scalp reconstruction. Arch Plast Surg 2013;40 (5):564-9.

[24] Van Driel AA, Mureau MA, Goldstein DP, et al. Aesthetic and oncologic outcome after microsurgical reconstruction of complex scalp and forehead defects after malignant tumor resection: an algorithm for treatment. Plast Reconstr Surg 2010;126 (2):460-70.
[25] Handschin AE, Jung FJ, Guggenheim M, et al. Surgical treatment of high-voltage electrical injuries. Handchir Mikrochir Plast Chir 2007;39 (5):345-9.

[26] Wright HR, Drake DB, Gear AJ, et al. Industrial high voltage electrical burn of the skull, a preventable injury. J Emerg Med 1997;15 (3):345-9.

[27] Handschin AE, Jung FJ, Guggenheim M, et al. Surgical treatment of high-voltage electrical injuries. Handchir Mikrochir Plast Chir 2007;39 (5):345-9.

[28] Zuker RM, Cleland HJ. Scalp reconstruction. In: Bardaeh J, edr. Local flaps and free skin grafts in head and neck reconstruction. St. Louis. Mosby Year Book 1992: p. 17992. 